\title{
Cell cycle arrest in mitosis promotes interferon-induced necroptosis
}

\author{
Tanja Frank ${ }^{1} \cdot$ Marcel Tuppi $\mathbb{D}^{2} \cdot$ Manuela Hugle ${ }^{1} \cdot$ Volker Dötsch $\mathbb{D}^{2} \cdot$ Sjoerd J. L. van Wijk $\mathbb{D}^{1} \cdot$ Simone Fulda $\mathbb{D}^{1,3,4}$
}

Received: 24 September 2018 / Revised: 21 January 2019 / Accepted: 22 January 2019 / Published online: 11 February 2019

(c) ADMC Associazione Differenziamento e Morte Cellulare 2019

\begin{abstract}
Resistance to apoptosis is a hallmark of cancer and deregulation of apoptosis often leads to chemoresistance. Therefore, new approaches to target apoptosis-resistant cancer cells are crucial for the development of directed cancer therapies. In the present study, we investigated the effect of cell cycle regulators on interferon (IFN)-induced necroptosis as an alternative cell death mechanism to overcome apoptosis resistance. Here, we report a novel combination treatment of IFNs with cell cycle arrest-inducing compounds that induce necroptosis in apoptosis-resistant cancer cells and elucidate the underlying molecular mechanisms. Combination treatment of IFNs (i.e. IFN $\beta$ ) with inhibitors of the cell cycle (e.g. vinorelbine (VNR), nocodazole (Noc), polo-like kinase-1 (Plk-1) inhibitor BI 6727) co-operate to induce necroptotic cell death upon caspase inactivation. The mode of cell death was confirmed by pharmacological inhibition and siRNA-mediated downregulation of the key necroptotic factors receptor-interacting protein (RIP) kinase 3 (RIP3) and mixed-lineage kinase-like (MLKL) in various cell lines. Mechanistically, we show that necroptosis upon VNR/IFN $\beta / z V A D . f m k$ treatment is RIP1-independent but relies on IFN $\beta$-induced gene expression of Z-DNA-binding protein 1 (ZBP1) as shown by quantitative RT-PCR and genetic knockdown experiments. Interestingly, we find that RIP3 is phosphorylated in response to compounds that trigger mitotic arrest, even in the absence of IFN $\beta$ signaling and necroptosis induction. Together, the identification of a novel combination treatment that triggers necroptosis has implications for the development of molecular-targeted therapies to circumvent apoptosis resistance and point to an underestimated role of cell cycle regulation in cell death signaling.
\end{abstract}

\section{Introduction}

Evasion of apoptosis has long been described as a hallmark of cancer [1] and contributes to tumorigenesis and chemoresistance [2], highlighting the need for novel targeted

These authors contributed equally: Sjoerd J.L. van Wijk, Simone Fulda

Edited by G. Kroemer

Supplementary information The online version of this article (https:// doi.org/10.1038/s41418-019-0298-5) contains supplementary material, which is available to authorized users.

Simone Fulda

simone.fulda@kgu.de

1 Institute for Experimental Cancer Research in Pediatrics, GoetheUniversity, Komturstr. 3a, 60528 Frankfurt am Main, Germany

2 Institute of Biophysical Chemistry and Center for Biomolecular Magnetic Resonance and Cluster of Excellence Macromolecular Complexes (CEF), Goethe-University, Frankfurt, Germany

3 German Cancer Consortium (DKTK), Heidelberg, Germany

4 German Cancer Research Center (DKFZ), Heidelberg, Germany treatment therapies. Apart from apoptosis, other types of cell death, such as necroptosis, ferroptosis, or pyroptosis have been described in different cellular settings [3]. Although necroptosis has long been regarded as an accidental form of cell death, recent evidence points to a tight regulation of necroptotic cell death. Key necroptosis mediators comprise the serine/threonine kinases, i.e. RIP1 and receptor-interacting protein kinase 3 (RIP3), as well as the pseudokinase MLKL [4]. The best understood necroptotic signaling cascade involves the tumor necrosis factor (TNF) pathway and is typically activated in the absence of cellular Inhibitors of Apoptosis (cIAPs) and diminished caspase activity [5]. In this context, TNF signaling induces the formation of complex II which is composed of RIP1, caspase-8, Fas-associated protein with death domain (FADD), and cellular FLICE-like inhibitory protein (c-FLIP). RIP1 then interacts with RIP3 through the RIP homotypic interaction motif (RHIM) domains. Following a series of autophosphorylation and cross-phosphorylation events, RIP3 becomes activated through phosphorylation, leading to subsequent phosphorylation and activation of MLKL by RIP3 [4, 5]. Phosphorylated MLKL oligomerizes and translocates to the plasma membrane, where it forms pores 
to execute cell death [6]. Nonetheless, other ways to initiate necroptosis, such as activation of toll-like receptors (TLRs) or sensing of viral DNA by cytosolic DNA sensors, have been described as well $[5,7,8]$. Recently, IFNs have been associated with necroptosis induction in several studies. However, their exact role remains elusive so far. During the innate immune response, IFNs induce the expression of hundreds of IFN-stimulated genes (ISGs), which are needed for diverse pathogen defense mechanisms [9]. In the context of necroptosis, it has been suggested that IFNs are required for sustained activation of RIP3 in macrophages [10], and that type I IFNs are crucial for expression of MLKL [11, 12]. Nevertheless, most studies agree that IFN signaling and concomitant induction of protein expression alone do not induce necroptosis but depend on additional factors, such as caspase inactivation or FADD translocation [12, 13].

One of the proteins transcriptionally regulated by IFNs is Z-DNA-binding protein 1 (ZBP1) [14]. Apart from its DNA-sensing function, ZBP1 has been described to interact with RIP1 and RIP3 via their respective RHIM domains, thereby potentially regulating nuclear factor-kappaB (NF$\kappa \mathrm{B})$ activation, viral infection, necroptotic signaling, and the induction of cell death [15-18].

Microtubule-targeting agents (MTAs), such as vinca alkaloids, are among the most successful chemotherapeutics [19]. MTAs interfere with microtubule dynamics, thereby halting cells in G2/M phase of the cell cycle and ultimately inducing apoptosis due to prolonged mitotic arrest [20]. However, effects of MTAs are often reduced in terms of apoptotic chemoresistance and side effects occur frequently due to the inhibition of microtubule dynamics in noncancerous cells [21, 22]. To increase therapeutic efficiency it is desirable to identify combinatory treatments allowing low doses of microtubule-targeting drugs to overcome apoptosis resistance. Therefore, in the present study we investigated the potential of IFNs together with cell cycle regulators, which halt cells in mitosis, to induce cell death.

\section{Material and methods}

\section{Cell culture and chemicals}

HT29 cells were obtained from DSMZ (Braunschweig, Germany), Capan-2 cells were kindly provided by Dieter Saur (Munich, Germany), wild-type (WT) and MLKL knockout (KO) mouse embryonic fibroblasts (MEFs) were a kind gift from Joanne Hildebrand (Walter and Eliza Hall Institute of Medical Research, Parkville, Australia), and RIP3 KO MEFs were kindly provided by Jiahuai Han (Xiamen University, Fujian, China). HT29 cells were maintained in McCoy's 5A Medium GlutaMAX ${ }^{\text {TM}}$-I (Life Technologies, Inc., Eggenstein, Germany) and MEFs and
Capan-2 cells in DMEM GlutaMAX ${ }^{\text {TM }}$-I medium (Life Technologies), both supplemented with $10 \%$ fetal calf serum (FCS) (Biochrom, Ltd., Berlin, Germany), 1\% penicillin/streptomycin (Invitrogen) and $1 \%$ sodium pyruvate (Gibco). Cells were cultured at $37^{\circ} \mathrm{C}$ in a humidified atmosphere with $5 \% \mathrm{CO}_{2}$, and were subcultured two or three times a week.

Vincristine (VCR), vinblastine (VBL), vinorelbine (VNR), nocodazole (Noc), and dimethylenastrone (DME) were purchased from Sigma; BV6 was kindly provided from Genentech, Inc. (South San Francisco, CA, USA); necrostatin-1s (Nec-1s), GSK'872, necrosulfonamide (NSA), IFN $\alpha$, IFN $\beta$, and IFN $\gamma$ were purchased from Merck (Darmstadt, Germany); Dabrafenib (Dab) from Selleckchem; BI 6727 from Boehringer Ingelheim (Vienna, Austria); carbobenzoxyvalyl-alanyl-aspartyl-[O-methyl]fluoromethylketone (zVAD.fmk) was purchased from Bachem (Heidelberg, Germany). $\lambda$-phosphatase from Santa Cruz (Heidelberg, Germany). If not indicated differently, chemicals were purchased from Carl Roth (Karlsruhe, Germany) or Sigma-Aldrich (Taufkirchen, Germany).

\section{Cell cycle analysis}

Cell cycle analysis using flow cytometry was performed on propidium iodide (PI)-stained nuclei as previously described [23] and analyzed using FlowJo software (TreeStar Inc., Ashland, OR, USA). The fraction of cells in mitosis was assessed by immunofluorescence staining or protein expression analysis of $\mathrm{pH} 3$.

\section{Determination of cell death}

Cell death was determined by PI/Hoechst uptake to assess plasma membrane integrity of cells incubated with $1 \mu \mathrm{g} / \mathrm{ml}$ of PI diluted in phosphate-buffered saline (PBS) for $10 \mathrm{~min}$ using ImageXpress Micro XLS system (Molecular devices, LLC, Biberach and der Riss, Germany), according to the manufacturer's instructions.

\section{RNA interference}

Transient genetic silencing of necroptotic target genes was performed by reverse transfection of cells with $20-30 \mathrm{nM}$ Silencer ${ }^{\bullet}$ Select siRNAs (Life Technologies, Inc.) using Lipofectamine ${ }^{\circledast}$ RNAiMax reagent (Life Technologies, Inc.), and Opti-MEM ${ }^{\circ}$ medium (Life Technologies, Inc.). Following siRNAs were used: human siRIP3 (\#1: s21740, \#2: s21741), siMLKL (\#1: s47087, \#2: s47088), human siZBP1 (\#1: s37484, \#2: s37485), and murine siZBP1 (\#1: s233870, \#2: s81548). Knockdown efficiency was confirmed by Western blot analysis or qRT-PCR. 


\section{Generation of BCL-2 overexpressing cell lines}

HT29 cells and MEFs stably overexpressing murine BCL-2 (mBCL-2) were generated by retroviral transduction as previously described [23]. Briefly, Phoenix cells were transfected with $20 \mu \mathrm{g}$ of pMSCV plasmid (empty or $\mathrm{mBCL}-2)$ using calcium phosphate transfection. Retroviruscontaining supernatants were collected $24 \mathrm{~h}$ after transfection and sterile filtered. Parental HT29 cells and MEFs were then transduced with $2 \mathrm{ml}$ retroviral supernatant containing $8 \mu \mathrm{g} / \mathrm{ml}$ polybrene. Transduced cells were selected using 10 $\mu \mathrm{g} / \mathrm{ml}$ blasticidine. BCL-2 plasmids were kindly provided by CA Schmitt (Berlin, Germany). Transduction efficiency was confirmed by Western blotting.

\section{Colony formation assay}

Colony formation assay was performed as previously described [23]. Briefly, 100 cells per well of a six-well plate were seeded and treated as indicated for $24 \mathrm{~h}$. Afterwards, cells were cultured for additional 5 (MEFs) to 9 (HT29 cells) days in drug-free medium before fixation and staining with $0.5 \%$ crystal violet, $30 \%$ ethanol, and $3 \%$ formaldehyde. Number of colonies was counted macroscopically and results were expressed as percentage of colonies relative to untreated controls.

\section{Western blot analysis}

Western blot analysis was performed as previously described [24] using the following antibodies: mouse anti- $\beta$-Actin (\#A5441, Sigma-Aldrich), mouse anti-BCL-2 (\#610538, BD Bioscience), rabbit anti-pBubR1 (S670) (ab200062, Abcam), mouse anti-BubR1 (ab54894, Abcam), mouse anti-GAPDH (\#5G4-6C5, HyTest, Ltd., Turku, Finland), rabbit anti-pH3 (S10) (\#06-570, Millipore), mouse anti-H3 (ab24834, Abcam), rabbit anti-human pMLKL (S358) (\#91689S, Cell Signaling, Beverly, MA, USA), rabbit antihuman MLKL (\#14993S, Cell Signaling, Beverly, MA, USA), rabbit anti-murine MLKL (orb32399, Biorbyt), mouse anti-cleaved poly(ADP ribose) polymerase (PARP) (\#9546S, Cell Signaling, Beverly, MA, USA), mouse antiRIP1 (\#610459, BD Bioscience, Heidelberg, Germany), rabbit anti-human RIP3 (\#13526S, Cell Signaling, Beverly, MA, USA), rabbit anti-murine RIP3 (\#PSC-2283-C100, Axxora), mouse anti-vinculin (\#V9131-100UL, Merck), and mouse anti-ZBP1 (clone Zippy-1, Adipogen). Goat anti-mouse $\operatorname{IgG}$ and goat anti-rabbit IgG conjugated to horseradish peroxidase (HRP) (Santa Cruz Biotechnology, Heidelberg, Germany) as secondary antibodies and enhanced chemiluminescence (Amersham Bioscience, Freiburg, Germany) were used for detection. Primary antibodies were diluted 1:1000 in PBS with $0.2 \%$ Tween 20
(PBS-T) containing $2 \%$ bovine serum albumin (2\% BSA) and secondary antibodies were diluted 1:10,000 in PBS-T with $5 \%$ milk powder. Representative blots of at least two independent experiments are shown.

\section{Immunofluorescence staining of pH3 (mitotic index assay)}

For immunofluorescence staining of the mitotic marker $\mathrm{pH} 3$, cells were fixed for $8 \mathrm{~min}$ in methanol at $-20^{\circ} \mathrm{C}$, blocked for $10 \mathrm{~min}$ in antibody dilution (ABD) buffer $(0.9 \%$ $\mathrm{NaCl}, 10 \mathrm{mM}$ Tris- $\mathrm{HCl} \mathrm{pH} 7.5,5 \mathrm{mM}$ EDTA, $1 \mathrm{mg} / \mathrm{ml}$ BSA, supplemented with 10\% FCS) and incubated with rabbit polyclonal anti-pH3 (1:1000) and mouse monoclonal anti- $\alpha$-tubulin-FITC (1:600; Sigma) for $1 \mathrm{~h}$, followed by CyTM3 AffiniPure Donkey Anti-Rabbit IgG (1:800; Jackson ImmunoResearch) for 30 min (antibodies diluted in ABD buffer with $10 \%$ FCS). Cells were counterstained with DAPI for 10 min at RT and stored in PBS until visualization using the ImageXpress Micro XLS system (Molecular devices, LLC, Biberach and der Riss, Germany).

\section{Size-exclusion chromatography (SEC)}

For SEC analysis, cells were harvested, washed with PBS and afterwards flash-frozen using liquid nitrogen in lysis buffer (30 mM Tris pH 7.5, $150 \mathrm{mM} \mathrm{NaCl}, 60 \mathrm{mM}$ CHAPS, $2 \mathrm{mM} \mathrm{MgCl}_{2} 1 \mathrm{x}$ cOmplete (Roche), 1x PhosStop (Roche)). Lysis of cells was achieved by three freeze and thaw cycles in liquid nitrogen and incubation for $1 \mathrm{~h}$ on ice together with $5 \mu$ benzonase (Sigma). Samples where centrifuged for 15 min at $13.2 \mathrm{krpm}$ at $4{ }^{\circ} \mathrm{C}$. Supernatant was applied to an analytical scale SEC column (Superose 6 PC 3.2/300) at $4^{\circ}$ C. In order to minimize the delay volume of the system, the flow cell was directly connected to the fractionation system (Frac950) with a glass fiber $(15 \mu$ delay volume). The column was equilibrated with SEC buffer $(30 \mathrm{mM}$ Tris $\mathrm{pH}$ $7.5,150 \mathrm{mM} \mathrm{NaCl}, 20 \mathrm{mM}$ CHAPS) at $0.05 \mathrm{ml} / \mathrm{min} .50 \mu \mathrm{l}$ sample volume was injected and separated at a flow rate of $0.05 \mathrm{ml} / \mathrm{min} .0 .05 \mathrm{ml}$ fractions were collected into a 96-well plate. The column was calibrated using the Gel Filtration Calibration Kits (LMW, HMW) (GE Healthcare Life Sciences).

\section{Quantitative real-time PCR (qRT-PCR)}

Total RNA was isolated using the peqGOLD Total RNA kit (Peqlab, Erlangen, Germany) according to the manufacturer's instructions. For cDNA synthesis, $1 \mu \mathrm{g}$ of total RNA was used to synthesize the corresponding cDNA using the RevertAid H Minus First Strand cDNA Synthesis kit (MBI Fermentas GmbH, St. Leon-Rot, Germany) according to the manufacturer's instructions. Quantification of gene 

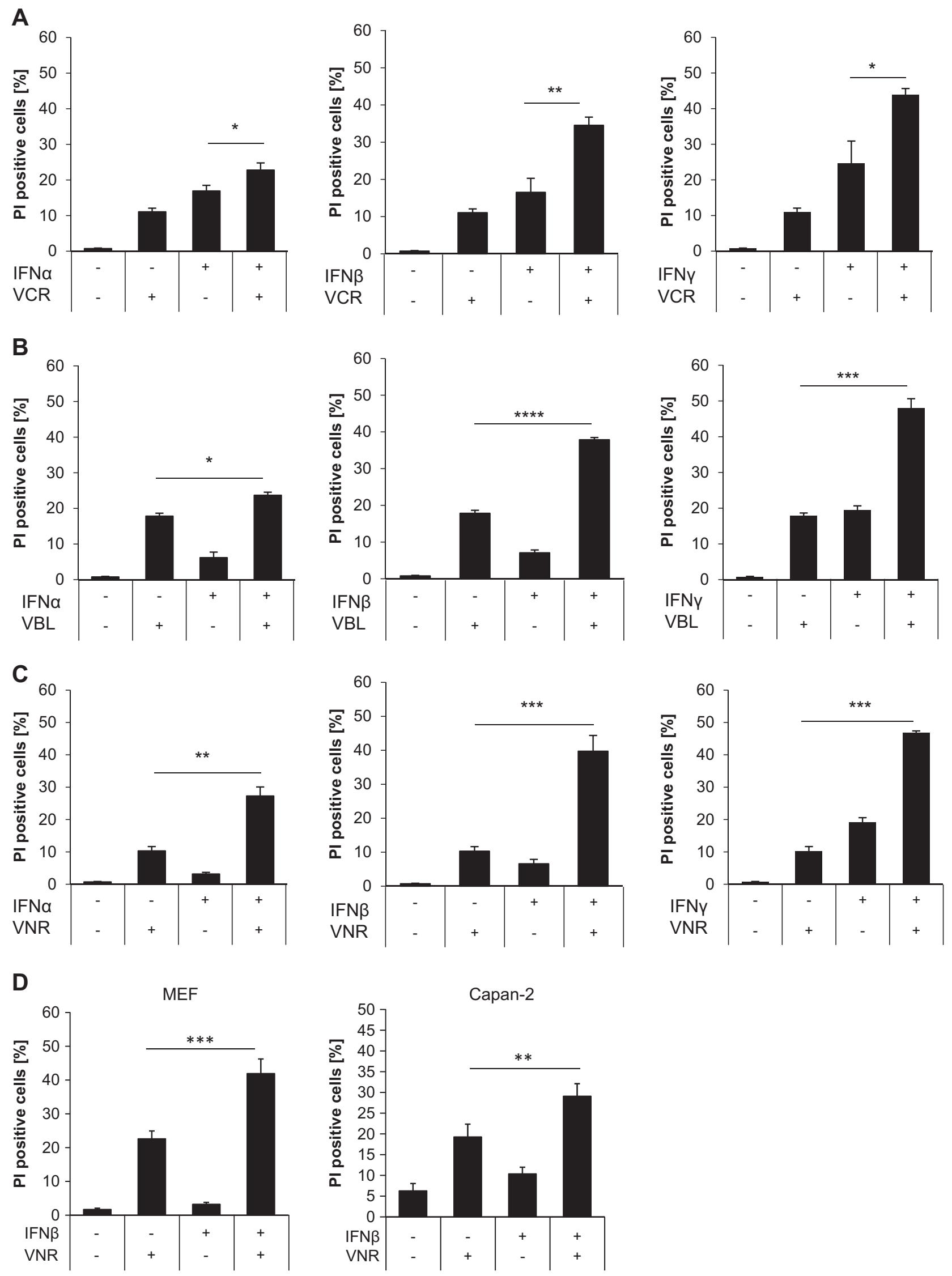
E

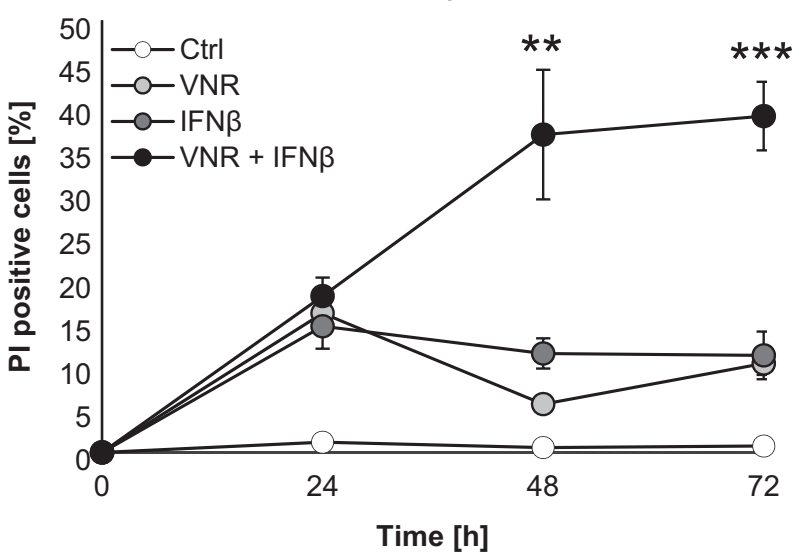

MEF

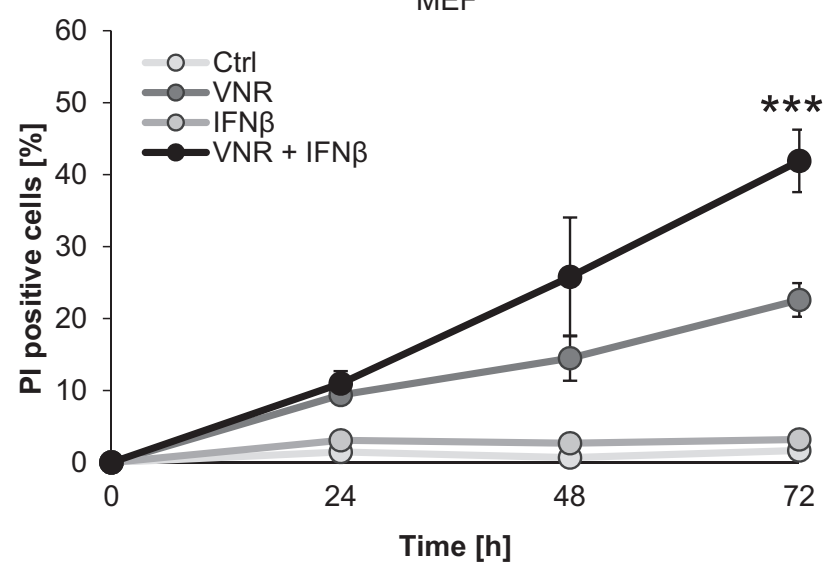

Fig. 1 Vinca alkaloids enhance IFN-induced cell death. a-c HT29 cells were treated with $10 \mathrm{ng} / \mathrm{ml}$ IFN $\alpha$, IFN $\beta$, or IFN $\gamma$ and/or $100 \mathrm{nM}$ VCR (a), VBL (b), or VNR (c) for $72 \mathrm{~h}$. Cell death was determined by analysis of PI-stained nuclei. Mean and SD of three independent experiments performed in triplicate are shown; $* P<0.05, * * P<0.01$, $* * * P<0.001, * * * * P<0.0001$. d MEFs and Capan-2 cells were treated with $10 \mathrm{ng} / \mathrm{ml}$ IFN $\beta$ (Capan-2) or $4.5 \mathrm{ng} / \mathrm{ml}$ murine IFN $\beta$ (MEFs) and/or $100 \mathrm{nM}$ VNR for $72 \mathrm{~h}$ (Capan-2) or $48 \mathrm{~h}$ (MEFs). Cell death was determined by analysis of PI-stained nuclei. Mean and SD of three independent experiments performed in triplicate are shown; $* * P<0.01, * * * P<0.001$. e HT29 cells and MEFs were treated with $10 \mathrm{ng} / \mathrm{ml}$ IFN $\beta$ (HT29) or $4.5 \mathrm{ng} / \mathrm{ml}$ murine IFN $\beta$ (MEFs) and/or $100 \mathrm{nM}$ VNR for the indicated time points. Cell death was determined by analysis of PI-stained nuclei. Mean and SD of three independent experiments performed in triplicate are shown; $* * P<0.01$, $* * * P<0.001$

expression was assessed by SYBR green-based qRT-PCR using the QuantStudio 7 Flex real-time PCR system (Applied Biosystems, Darmstadt, Germany). Data were normalized to human 28S-rRNA or murine GAPDH expression as reference. Relative expression levels of target transcripts were calculated and compared to the reference transcript using the $\Delta \Delta c_{\mathrm{t}}$-method. At least three independent experiments in triplicate were performed for each gene. Primers were purchased from Eurofins (Hamburg, Germany) or QuantiTect (Qiagen, Hilden, Germany).

\section{Statistical analysis}

Statistical significance was assessed by Student's $t$-test (two-tailed distribution, two-sample, equal variance). Data were expressed as mean $\pm \mathrm{SD}$ of three or more independent experiments performed in triplicate, if not stated otherwise. $P$-values $<0.05$ were considered statistically significant and indicated as following: $* P<0.05 ; * * P<0.01 ; * * * P<$ 0.001 .

\section{Results}

\section{Vinca alkaloids enhance IFN-induced cell death}

IFN signaling has been described to be involved in cell death induction, but often requires additional signals like Bid activation or caspase inhibition, to execute apoptosis or necroptosis, respectively [13, 25]. MTAs, which arrest cells in mitosis, are commonly used as chemotherapeutics for a wide range of malignancies. However, many tumors have developed chemoresistance towards these drugs, which allows them to evade cell death induction [26]. In order to sensitize cancer cell lines to IFN-induced cell death, we first tested sub-toxic concentrations of type I and type II IFNs alone and in combination with the vinca alkaloids VCR, VBL, or VNR in the colon adenocarcinoma cell line HT29 (data not shown). Interestingly, different IFNs (IFN $\alpha$, IFN $\beta$, and IFN $\gamma$ ) cooperated with several vinca alkaloids (VCR, VNR, VBL) to induce cell death as determined by the analysis of the uptake of PI, a marker for plasma membrane permeabilization and cell death (Fig. 1a-c). Cell death induction using IFN $\alpha$ in combination with all three vinca alkaloids was less potent compared to IFN $\beta$ and IFN $\gamma$. Notably, we observed that combining the semisynthetic VBL-derivative VNR with IFN $\beta$ induced the most prominent effects on cell death induction compared to the relatively limited activity of the single treatment (Fig. 1a-c). Furthermore, combination treatment of IFN $\beta$ with VNR also cooperatively induced cell death in MEFs and the pancreatic adenocarcinoma cell line Capan-2 (Fig. 1d). Further analysis of cell death kinetics showed a time dependency of VNR/IFN $\beta$-induced cell death in both HT29 cells and MEFs (Fig. 1e). Taken together, these findings indicate that vinca alkaloids enhance IFN-induced cell death in several human cancer cell lines. 
A

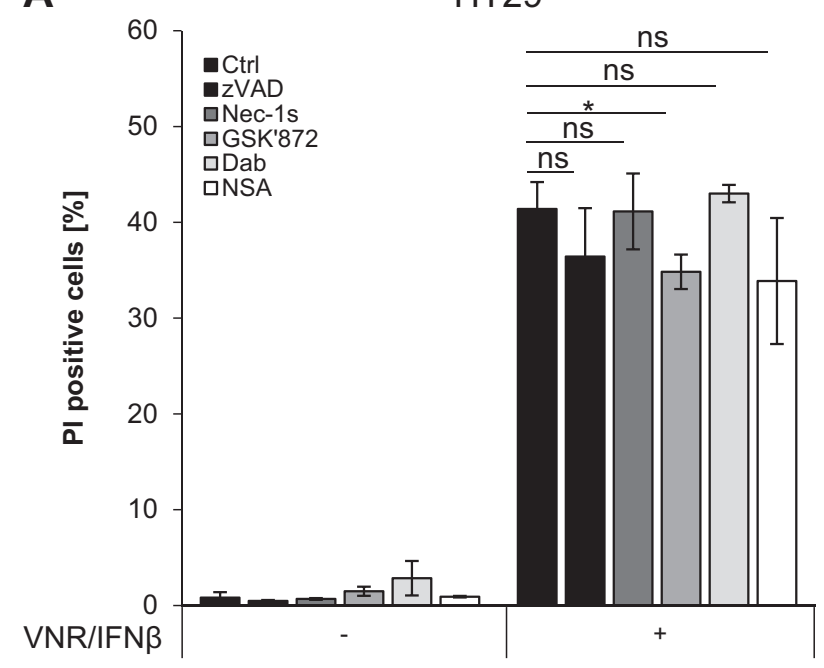

B

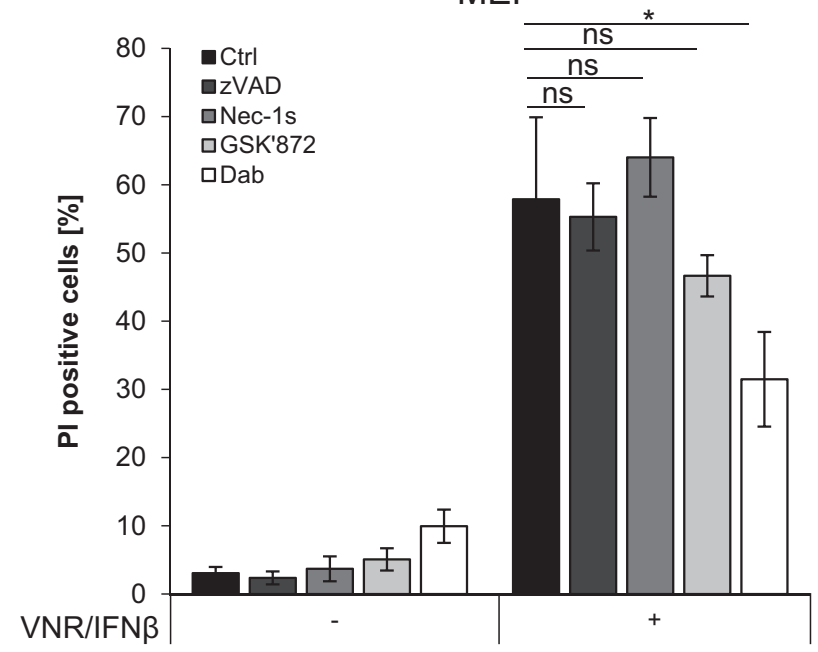

C

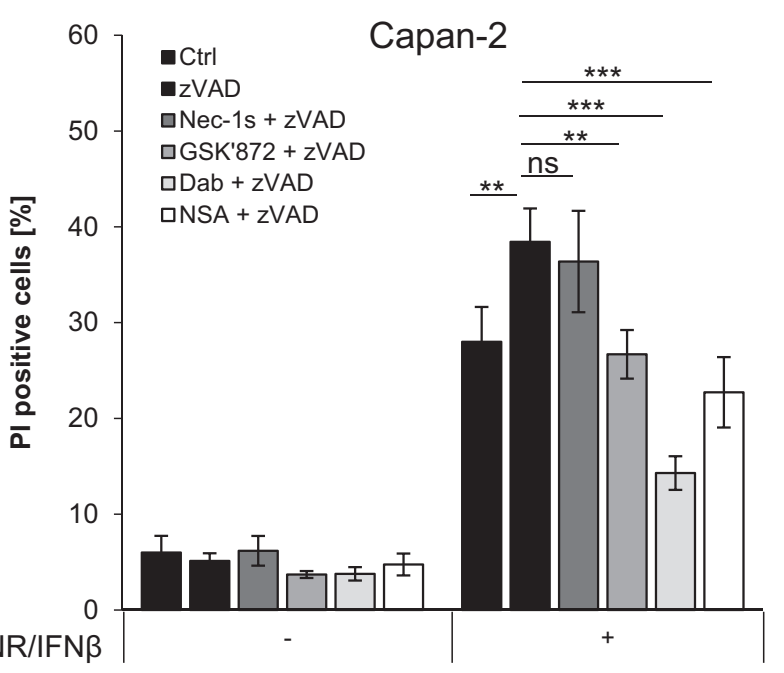

HT29

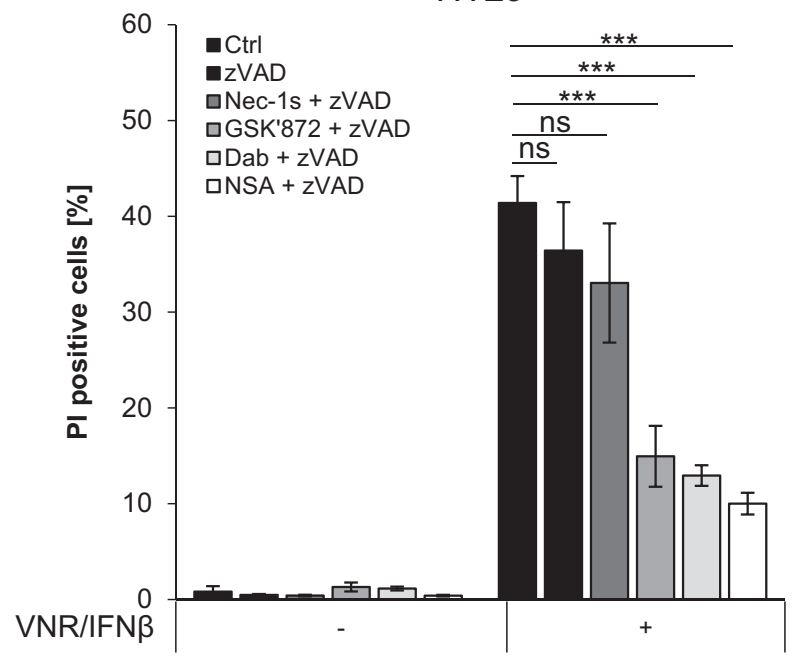

MEF

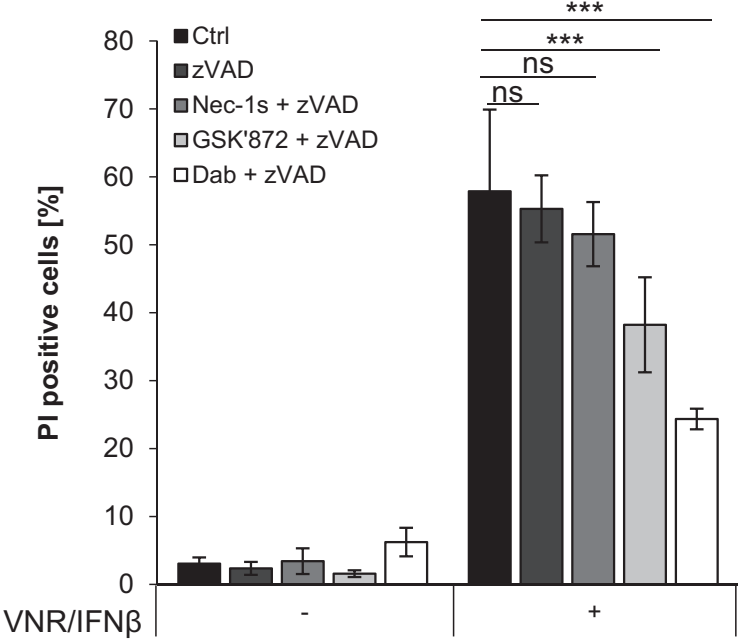

D

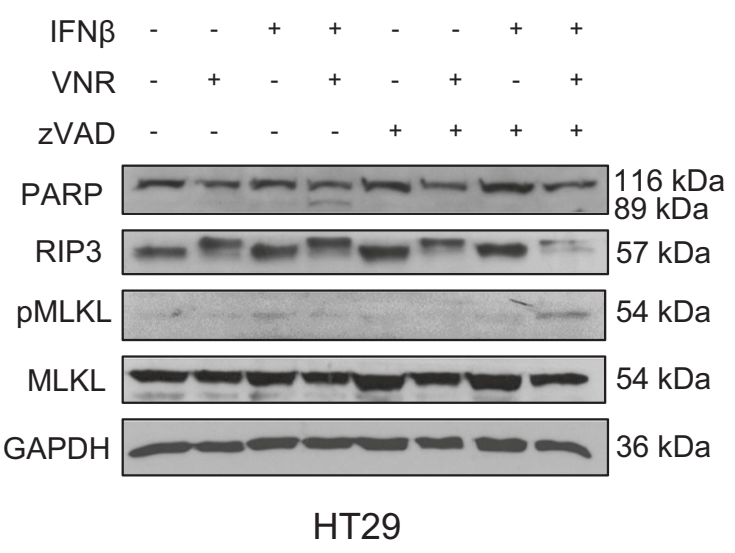


Fig. 2 Caspase inhibition induces a switch from apoptosis to necroptosis upon VNR and IFN $\beta$ co-treatment. a HT29 cells were treated with $10 \mathrm{ng} / \mathrm{ml} \mathrm{IFN} \beta, 100 \mathrm{nM}$ VNR, and/or $20 \mu \mathrm{M}$ zVAD.fmk in the presence or absence of $30 \mu \mathrm{M}$ Nec-1s, $10 \mu \mathrm{M}$ NSA, $20 \mu \mathrm{M}$ GSK' 872 , or $20 \mu \mathrm{M}$ Dab for $72 \mathrm{~h}$. Cell death was determined by analysis of PIstained nuclei. Mean and SD of three independent experiments performed in triplicate are shown; $* P<0.05$, $* * P<0.01$, $* * * P<0.001$, $\mathrm{ns}=$ not significant. $\mathbf{b}$ MEFs were treated with $4.5 \mathrm{ng} / \mathrm{ml}$ murine IFN $\beta$, $100 \mathrm{nM}$ VNR, and/or $20 \mu \mathrm{M} \mathrm{zVAD}$.fmk in the presence or absence of $30 \mu \mathrm{M}$ Nec-1s, $10 \mu \mathrm{M}$ GSK' 872 or $10 \mu \mathrm{M}$ Dab for $48 \mathrm{~h}$. Cell death was determined by analysis of PI-stained nuclei. Mean and SD of three independent experiments performed in triplicate are shown; $* P<0.05$, $* * * P<0.001$, ns $=$ not significant. c Capan-2 cells were treated with $10 \mathrm{ng} / \mathrm{ml} \mathrm{IFN} \beta, 100 \mathrm{nM}$ VNR, and/or $20 \mu \mathrm{M}$ zVAD.fmk in the presence or absence of $30 \mu \mathrm{M} \mathrm{Nec}-1 \mathrm{~s}, 10 \mu \mathrm{M}$ NSA, $20 \mu \mathrm{M}$ GSK' 872 , or $20 \mu \mathrm{M}$ Dab for $72 \mathrm{~h}$. Cell death was determined by analysis of PIstained nuclei. Mean and SD of three independent experiments performed in triplicate are shown; $* * P<0.01$, $* * * P<0.001$. d HT29 cells were treated with $10 \mathrm{ng} / \mathrm{ml}$ IFN $\beta, 100 \mathrm{nM}$ VNR, and/or $20 \mu \mathrm{M}$ zVAD. fmk for $24 \mathrm{~h}$. Protein expression of cleaved PARP, RIP3, pMLKL, MLKL, and GAPDH was analyzed by Western blotting. GAPDH served as loading control, $\mathrm{ns}=$ not significant.

\section{VNR and IFN $\beta$ induce necroptosis when the function of caspases is compromised}

When trying to elucidate the underlying molecular mechanisms of VNR/IFN $\beta$-induced cell death, the broadrange pan-caspase inhibitor zVAD.fmk surprisingly failed to block cell death in all tested cell lines (Fig. 2a-c). Similar results were obtained using the caspase-3- and caspase-9selective inhibitors zDEVD.fmk and zLEHD.fmk, respectively (Supplementary Figure 1). To investigate the possibility that IFN $\beta$ in combination with VNR promotes necroptotic cell death we tested pharmacological inhibitors of key mediators of necroptosis, i.e. RIP1, RIP3, and MLKL. However, addition of the RIP1 inhibitor Nec-1s, the RIP3 inhibitor GSK'872, as well as the MLKL inhibitor NSA alone did not abrogate VNR/IFN $\beta$-induced cell death (Fig. 2a, b). Only Dab was able to significantly inhibit VNR/IFN $\beta$-induced cell death in MEFs (Fig. 2b) but not in HT29 cells (Fig. 2a). Interestingly, combined inhibition of caspases and RIP3 or MLKL significantly rescued cell death in HT29 cells and MEFs (Fig. 2a, b). In Capan-2 cells, inhibition of caspases by zVAD.fmk even elevated the amount of cell death (Fig. 2c). This enhanced effect on cell death was reversed by additional inhibition of RIP3 or MLKL using GSK'872, Dab, or NSA (Fig. 2c). Intriguingly, RIP1 inhibition using Nec-1s had no further effect on VNR/IFN $\beta / z V A D$.fmk-induced cell death in all cell lines tested (Fig. 2a-c), although Nec-1s efficiently blocked necroptosis induced by a prototypic necroptotic stimulus, i.e. combination treatment of the Smac mimetic BV6 with zVAD.fmk (Supplementary Figure 2). Remarkably, VNR/ IFN $\beta$ co-treatment in the presence but not in the absence of zVAD.fmk induced phosphorylation of MLKL, reminiscent of necroptosis (Fig. 2d). In parallel, caspase-dependent PARP cleavage, an apoptotic marker, was blocked upon addition of zVAD.fmk (Fig. 2d), pointing to a switch from apoptotic to necroptotic cell death upon caspase inhibition.

Apart from pharmacological inhibitors, we also applied genetic silencing of key necroptosis proteins to confirm that cells die through necroptosis. Importantly, siRNA-mediated knockdown of RIP3 or MLKL in HT29 cells significantly reduced cell death upon VNR/IFN $\beta / z V A D$.fmk treatment (Fig. 3a-d). Consistently, CRISPR/Cas9-mediated KO of RIP3 or MLKL significantly blocked VNR/IFN $\beta / z$ VAD. fmk-induced cell death in HT29 cells (Supplementary Figure 3). In addition, RIP3 or MLKL KO in MEFs as a typical cellular model of necroptosis significantly reduced VNR/ IFN $\beta / z V A D$.fmk-induced cell death as well (Fig. 3e-h). A key hallmark of necroptosis is the formation of the necrosome, composed of RIP1 and RIP3 that mediates phosphorylation and activation of MLKL. To verify that VNR/ IFN $\beta / z V A D$.fmk treatment indeed induces necrosome formation we analyzed the migration behavior of RIP1, RIP3, and MLKL, using SEC. In untreated MEFs, RIP1, RIP3, and MLKL, migrated exclusively at their corresponding molecular weights (Fig. 3i). However, after treating the cells with $\mathrm{TNF} \alpha / \mathrm{BV} 6 / \mathrm{zVAD}$ (TBZ) as a positive control or with

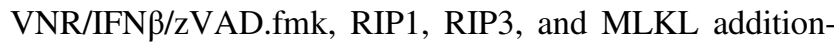
ally migrated in high molecular weight complexes, indicating that these proteins are involved in the formation of high molecular weight necrosomes (Fig. 3i and Supplementary Figure 4). To investigate the effects of the VNR/ IFN $\beta$ combination on long-term clonogenic survival, we assessed colony formation. Of note, in the presence and absence of zVAD.fmk VNR/IFN $\beta$ suppressed colony formation (Supplementary Figure 5), showing that VNR/IFN $\beta$ induced necroptosis ultimately reduces clonogenic survival.

Together, these findings demonstrate that cell death induced by VNR/IFN $\beta / z V A D$.fmk treatment switches from apoptosis to necroptosis upon caspase inhibition.

\section{RIP3 is phosphorylated during mitotic arrest upon vinca alkaloid treatment}

Vinca alkaloids are well-known for their ability to arrest cells in mitosis. To confirm that VNR indeed induces a mitotic arrest, we performed cell cycle analysis using flow cytometry. FACS analysis showed that the majority of cells were indeed arrested in G2/M upon VNR treatment (Fig. 4a). To distinguish between cell cycle arrest in G2 or mitosis, we applied immunofluorescent analysis of the mitotic marker histone $\mathrm{H} 3$ phosphorylation ( $\mathrm{pH} 3)$. Of note, both immunofluorescent staining (Fig. 4b), as well as Western blot analysis showed a marked increase of the mitotic marker $\mathrm{pH} 3$ upon VNR treatment (Fig. 4c). 

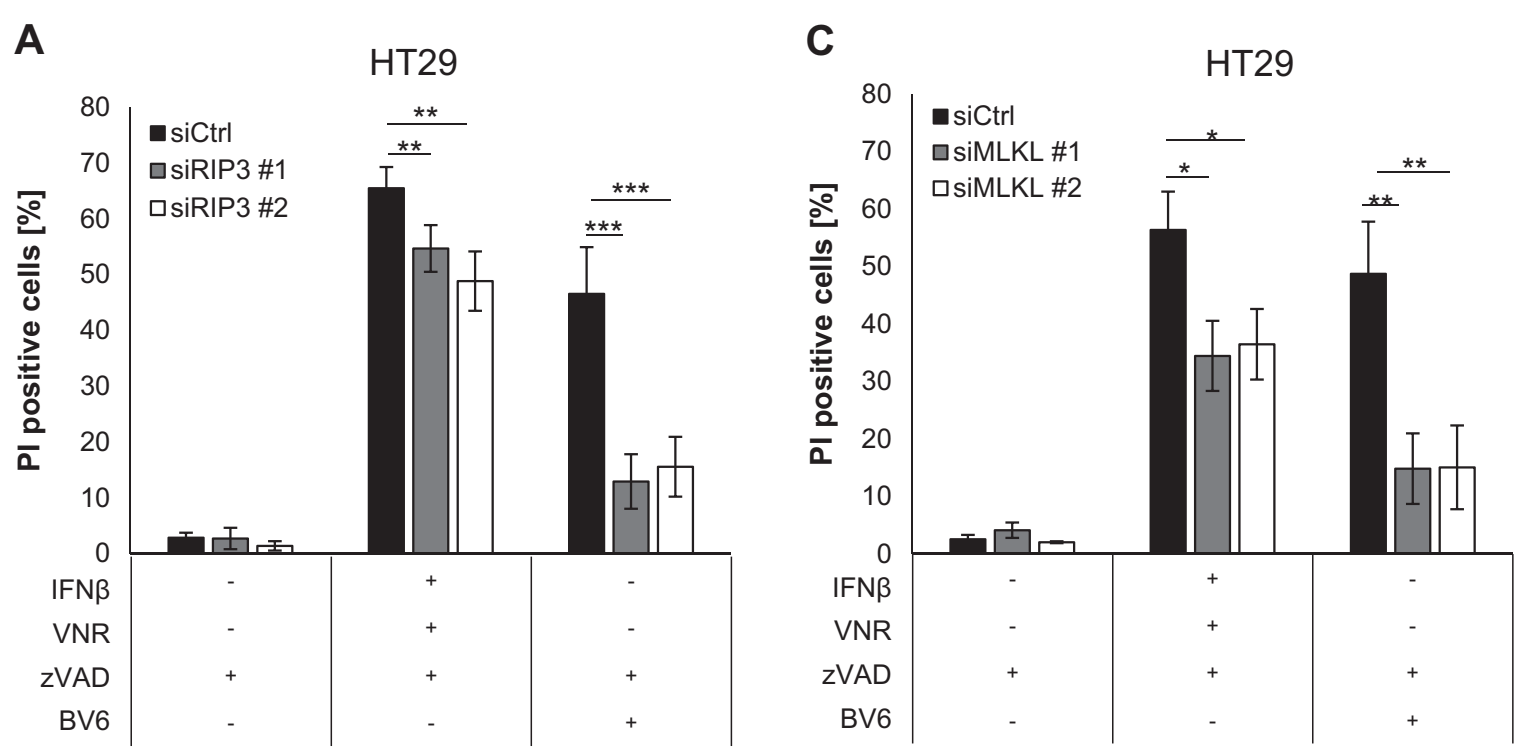

B

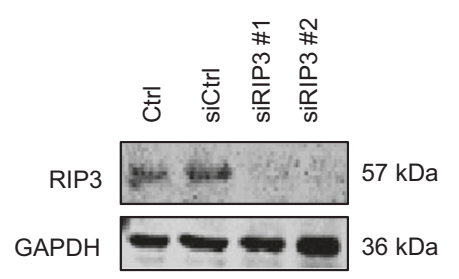

D

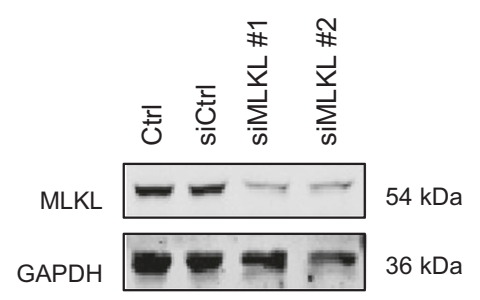

E

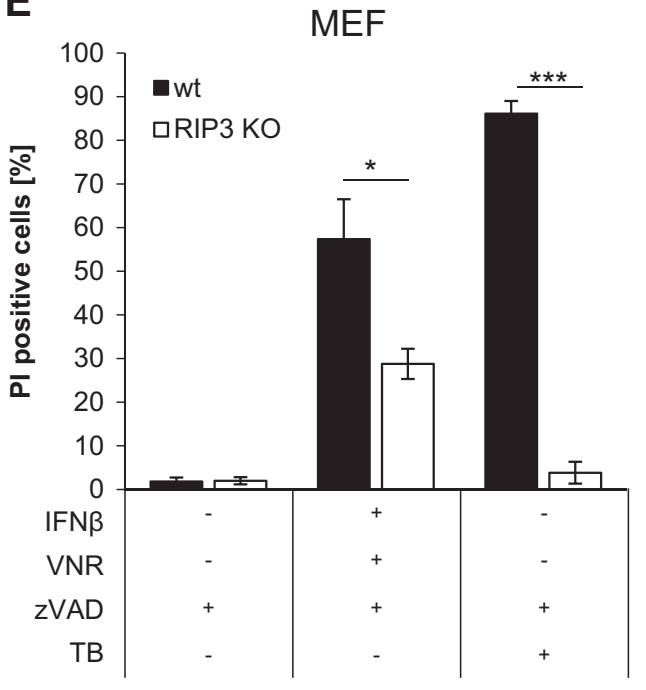

G

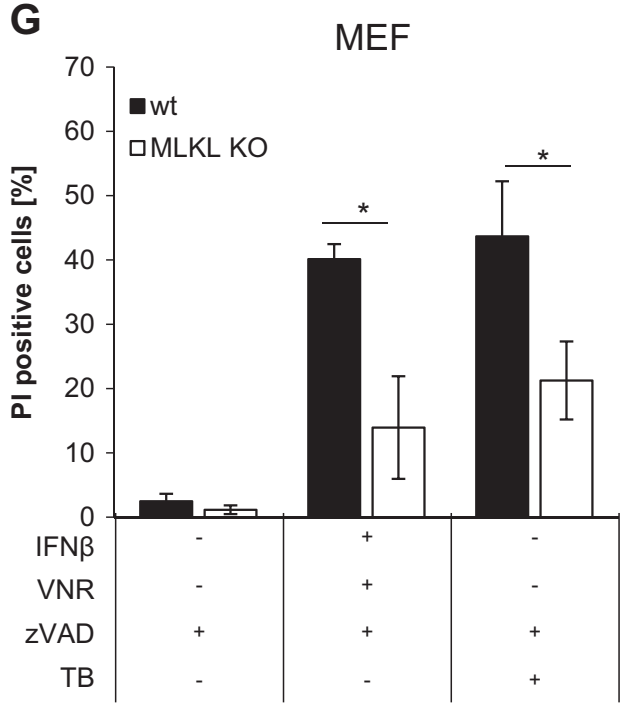

F

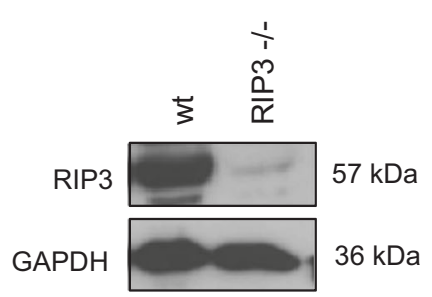

H

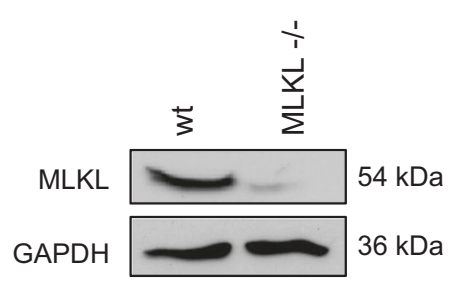




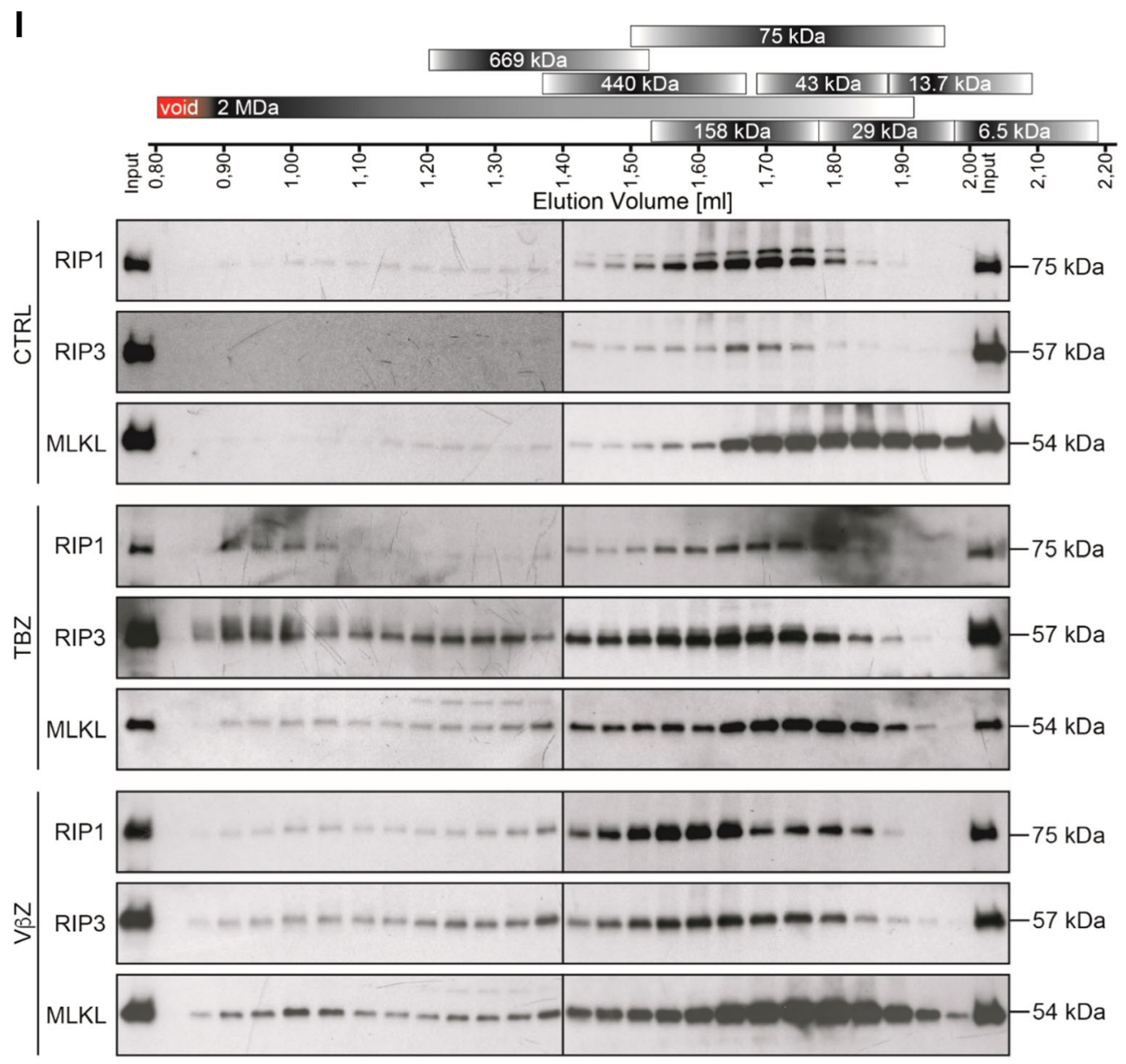

Fig. 3 Loss of RIP3 or MLKL inhibits VNR/IFN $\beta / z V A D$.fmk-induced necroptosis. a-d HT29 cells were transiently transfected with siRNA against RIP3 (a, b) or MLKL (c, d) or non-targeting control siRNA (siCtrl). Transfected cells were treated with $10 \mathrm{ng} / \mathrm{ml}$ IFN $\beta, 100 \mathrm{nM}$ VNR, $20 \mu \mathrm{M} z$ VAD.fmk, and/or $1 \mu \mathrm{M}$ BV6 for $72 \mathrm{~h}$ and cell death was determined by analysis of PI-positive nuclei. Mean and SD of three independent experiments performed in triplicate are shown; $* P<0.05$, $* * P<0.01, * * * P<0.001(\mathbf{a}, \mathbf{c})$. Expression of RIP3 and MLKL was assessed by Western blotting, with GAPDH serving as loading control (b, d). e-h Wt MEFs and MEFs deficient for RIP3 or MLKL were treated with $4.5 \mathrm{ng} / \mathrm{ml}$ murine IFN $\beta, 100 \mathrm{nM} \mathrm{VNR}, 20 \mu \mathrm{M}$ zVAD.fmk, $10 \mathrm{ng} / \mathrm{ml} \mathrm{TNF} \alpha$, and/or $5 \mu \mathrm{M}$ BV6 for $72 \mathrm{~h}$ (IFN $\beta / \mathrm{VNR} / \mathrm{zVAD}$.fmk) or

Interestingly, we also observed by Western blotting an upwards band of RIP3 upon VNR treatment (Fig. 4c). This slower migrating band shift was consistently observed also for other vinca alkaloids that cause mitotic arrest as confirmed by $\mathrm{pH} 3$ staining (Fig. 4c). Mobility shifts of proteins on SDS-PAGE are often due to phosphorylation of the protein of interest, as it has been shown for RIP1 and RIP3 during necroptosis induction [27]. Notably, $\lambda$-phosphatase treatment markedly reduced the observed band shift of RIP3, indicating that the slower migrating RIP3 fraction is indeed due to phosphorylation (Fig. 4d). As a positive control, phosphorylation of Budding uninhibited by
$5 \mathrm{~h}$ (TBZ) and cell death was determined by analysis of PI-positive nuclei. Mean and SD of three independent experiments performed in triplicate are shown; $* P<0.05, * * * P<0.001(\mathbf{e}, \mathbf{g})$. Expression of RIP3 and MLKL was assessed by Western blotting, with GAPDH serving as loading control (f, h). i MEFs were treated with $4.5 \mathrm{ng} / \mathrm{ml}$ murine IFN $\beta, 100 \mathrm{nM}$ VNR, and $20 \mu \mathrm{M}$ zVAD.fmk for $72 \mathrm{~h}$ or with $10 \mathrm{ng} / \mathrm{ml} \mathrm{TNF} \alpha, 5 \mu \mathrm{M}$ BV6, and $20 \mu \mathrm{M}$ zVAD.fmk for $2 \mathrm{~h}$. Lysates were fractionated on a Superose $63.2 / 300$ GL column and the resulting fractions, as well as input samples, were analyzed by Western blotting (i). A schematic representation of the calibration, which is shown in detail in Supplementary Figure 4, is depicted above the Western blots

benzimidazoles-related 1 (BubR1) decreased after $\lambda$-phosphatase treatment (Fig. 4d).

RIP3 phosphorylation has been described to occur at S199 (murine S204) and depends on its own kinase activity [27]. To further test whether RIP3 kinase activity is responsible for the observed band shift we applied the RIP3 inhibitor GSK'872. Addition of GSK'872, however, failed to abolish the band shift of RIP3, while it prevented phosphorylation of MLKL (Fig. 4e), indicating that VNRstimulated RIP3 phosphorylation is not mediated by the kinase activity of RIP3 itself. RIP3 has also been described to be phosphorylated by RIP1 at S227 to execute 
A

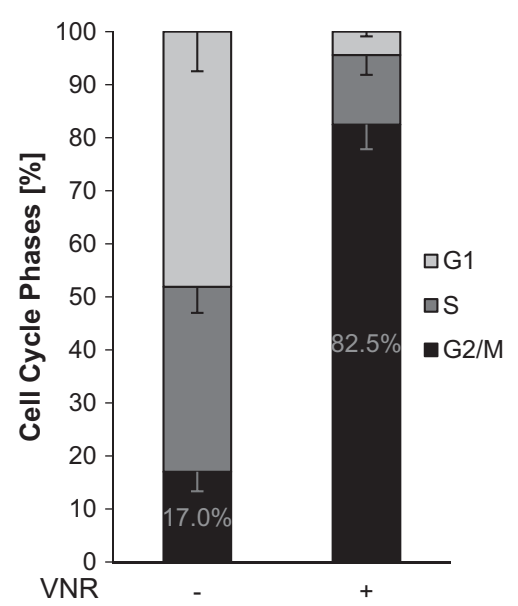

C

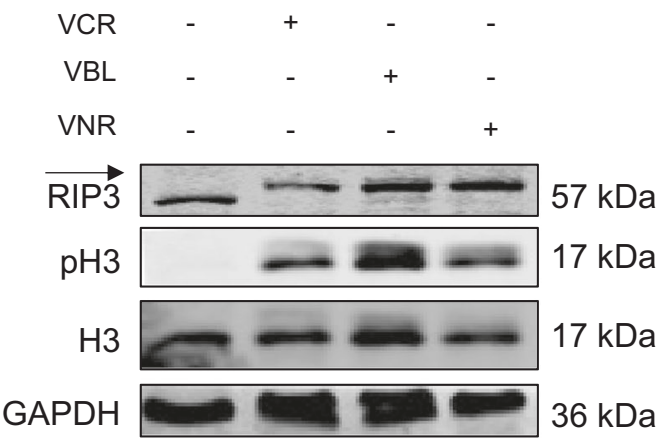

B

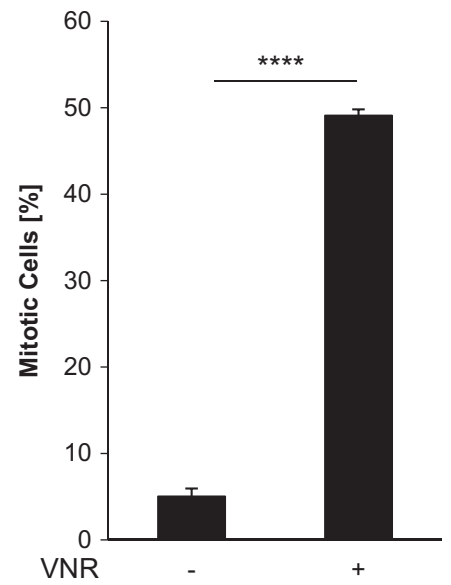

E

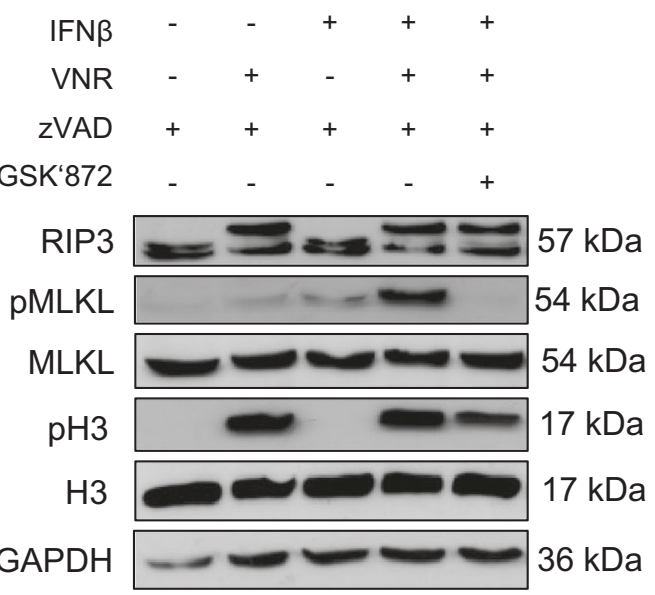

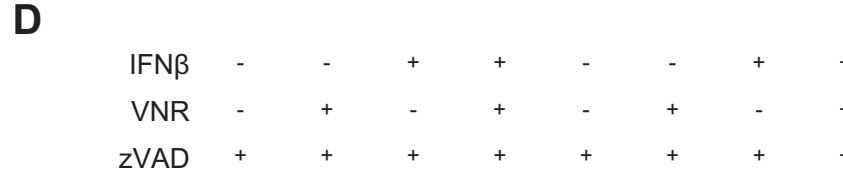

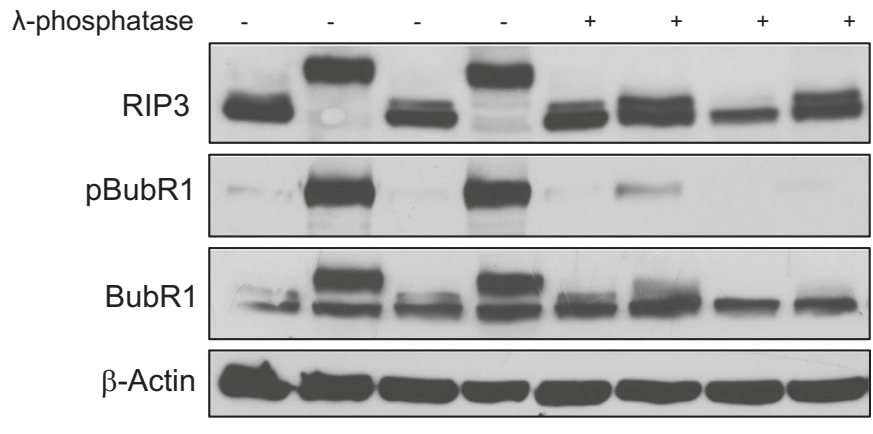

$\mathbf{F}$

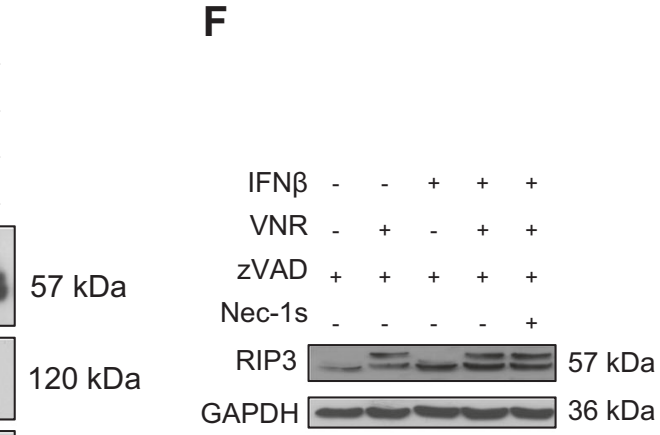

$120 \mathrm{kDa}$

$42 \mathrm{kDa}$ necroptosis [28]. However, addition of Nec-1s to block RIP1 kinase activity also had no effect on the mobility shift of RIP3 (Fig. 4f). In summary, these experiments demonstrate that RIP3 is phosphorylated during mitotic arrest caused by vinca alkaloids and indicate that this RIP3 phosphorylation occurs independently of RIP1 or its own kinase activity.
Cell cycle arrest in mitosis induces RIP3 phosphorylation and enhances IFN $\beta$-induced necroptosis

To further investigate whether cell cycle arrest in mitosis drives RIP3 phosphorylation and enhances IFN $\beta$-stimulated necroptosis, additional mitotic arrest-inducing drugs, i.e. the 
Fig. 4 RIP3 is phosphorylated during mitotic arrest upon vinca alkaloid treatment. a Fraction of cells per cell cycle phase was analyzed at $24 \mathrm{~h}$ after treatment with $100 \mathrm{nM}$ VNR in PI-stained nuclei using FlowJow software (TreeStar Inc.). Mean and SD of three independent experiments performed in triplicate are shown. b Mitotic cells upon treatment with $100 \mathrm{nM}$ VNR were quantified at $24 \mathrm{~h}$ by expression of mitotic marker $\mathrm{pH} 3$ using immunofluorescence. Mean and SD of three independent experiments performed in triplicate are shown; $* * * * P<$ 0.0001 . c HT29 cells were treated with $100 \mathrm{nM}$ VCR, VBL, or VNR for $24 \mathrm{~h}$. Protein expression of RIP3, pH3, H3, and GAPDH was analyzed by Western blotting. GAPDH served as loading control. d HT2 2 cells were treated with $10 \mathrm{ng} / \mathrm{ml}$ IFN $\beta, 100 \mathrm{nM}$ VNR, and/or 20 $\mu \mathrm{M}$ zVAD for $24 \mathrm{~h} .100 \mu \mathrm{g}$ of each lysate was incubated with $400 \mathrm{U} / \mu \mathrm{l}$ $\lambda$-phosphatase for $30 \mathrm{~min}$ and $30^{\circ} \mathrm{C}$ to remove phospho-groups. Protein expression of RIP3, pBubR1, BubR1, and $\beta$-Actin was analyzed by Western blotting. $\beta$-Actin served as loading control. e HT29 cells were treated with $10 \mathrm{ng} / \mathrm{ml} \mathrm{IFN} \beta, 100 \mathrm{nM}$ VNR, $20 \mu \mathrm{M}$ zVAD.fmk, and/or $20 \mu \mathrm{M}$ GSK' 872 for $24 \mathrm{~h}$. Protein expression of RIP3, pMLKL, MLKL, pH3, H3, and GAPDH was analyzed by Western blotting. GAPDH served as loading control. f HT29 cells were treated with 10 ng/ml IFN $\beta, 100 \mathrm{nM}$ VNR, $20 \mu \mathrm{M}$ zVAD.fmk, and/or $30 \mu \mathrm{M}$ Nec-1s for $24 \mathrm{~h}$. Protein expression of RIP3 and GAPDH was analyzed by Western blotting. GAPDH served as loading control

polo-like kinase-1 (Plk-1) inhibitor BI 6727, the MTA Noc, and the Eg5-kinesin inhibitor DME, were tested. Cell cycle analysis by flow cytometry confirmed that all compounds indeed arrested cells in G2/M phase (Supplementary Figure 6A). Furthermore, immunofluorescent staining and Western blot analysis of the mitotic marker $\mathrm{pH} 3$ confirmed that cells were arrested in mitosis upon treatment with the indicated cell cycle regulators (Supplementary Figure 6B, C). Importantly, BI 6727, Noc, and DME all stimulated phosphorylation of RIP3 (Fig. 5a). In addition, these drugs also cooperated with IFN $\beta$ to induce cell death (Fig. 5b). Of note, parallel addition of zVAD.fmk and NSA or GSK' 872 significantly reduced cell death induced by IFN $\beta$ together with BI 6727, Noc or DME, while zVAD.fmk alone failed to inhibit cell death (Fig. 5c). Consistent with necroptotic cell death, phosphorylation of MLKL occurred upon combination treatments with IFN $\beta$ together with BI 6727, Noc, or DME (Fig. 5a). By comparison, arresting cells in $\mathrm{S}$ phase by using the pyrimidine deoxynucleoside Thymidine failed to stimulate RIP3 phosphorylation and to enhance IFN $\beta$-stimulated necroptosis (Supplementary Figure 7). These data show that RIP3 is phosphorylated during mitosis and that cell cycle arrest in M phase enhances IFN $\beta$ induced necroptosis.

\section{ZBP1 upregulation upon IFN $\beta$-treatment is crucial for cell death induction after VNR/IFN $\beta / z V A D . f m k$ treatment}

IFN $\beta$ regulates the expression of many ISGs [29, 30]; therefore, we investigated the expression of putative target genes that might be involved in necroptotic signaling. qRTPCR analysis revealed that ZBP1 is highly upregulated upon IFN $\beta / z V A D$.fmk and VNR/IFN $\beta / z V A D$.fmk treatment (Fig. 6a). Western blot analysis confirmed enhanced protein expression for ZBP1 in MEF cells after IFN $\beta$ treatment (Fig. 6b). Remarkably, knockdown of ZBP1 significantly blocked necroptosis induction in HT29 cells and MEFs (Fig. 6c-g). Together, these data show that VNR/IFN $\beta / z V A D$.fmk-induced necroptosis is promoted by IFN $\beta$-induced expression of ZBP1.

Recently, ZBP1 activation has been linked to cytosolic release of mitochondrial DNA (mtDNA) and mitochondrial permeabilization, thereby promoting necroptosis [31-33]. The antiapoptotic protein BCL-2 is known to block mitochondrial pore formation and subsequent release of mitochondrial content into the cytoplasm [34]. To evaluate whether mitochondrial permeabilization is involved in VNR/IFN $\beta / z V A D$.fmk-induced necroptosis, we generated BCL-2-overexpressing MEFs and HT29 cells, and assessed cell death upon VNR/IFN $\beta / z V A D$.fmk treatment. However, overexpression of BCL-2 had no effect on VNR/IFN $\beta$ / zVAD.fmk-induced cell death (Supplementary Figure 8), indicating that cell death is likely not primarily engaged via mitochondrial permeabilization.

\section{Discussion}

In the present study, we identify a cell cycle-dependency of IFN $\beta$-induced necroptosis when caspase function is compromised. We demonstrate that cell cycle arrest in mitosis induced by different cell cycle-regulatory drugs, such as the microtubule dynamics-interfering vinca alkaloids or Noc, as well as Plk-1 inhibition and Eg5 inhibition, induces phosphorylation of RIP3 and promotes necroptosis induction when caspases are inhibited. The clinical relevance of our findings is underscored by the fact that cell death is induced in different cell types using several cell cycle-regulatory drugs and various type I and type II IFNs.

We have unraveled the underlying molecular mechanisms of the combination treatment of IFN $\beta$ with different cell cycle regulators. Both genetic and pharmacological rescue experiments confirm that combination of IFN $\beta$ with drugs arresting cells in mitosis triggers necroptotic cell death when caspases are inhibited. We show that individual knockdown or KO of RIP3 or MLKL protects cells from necroptosis induced by VNR/IFN $\beta / z V A D$.fmk cotreatment. In addition, pharmacological inhibition of RIP3 or MLKL inhibits VNR/IFN $\beta / z V A D$.fmk-induced cell death. By comparison, the use of Nec-1s to block RIP1 kinase activity had no effect on VNR/IFN $\beta / z V A D$.fmkinduced cell death, pointing to a RIP1 kinase activityindependent form of necroptosis. It has to be noted, though, that the reduction in VNR/IFN $\beta / z V A D$.fmk-induced cell death upon pharmacological or genetic inhibition of RIP3 or 
A
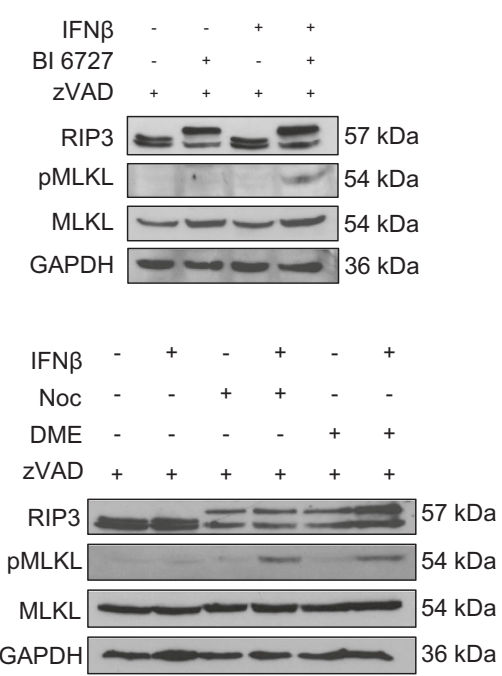

B
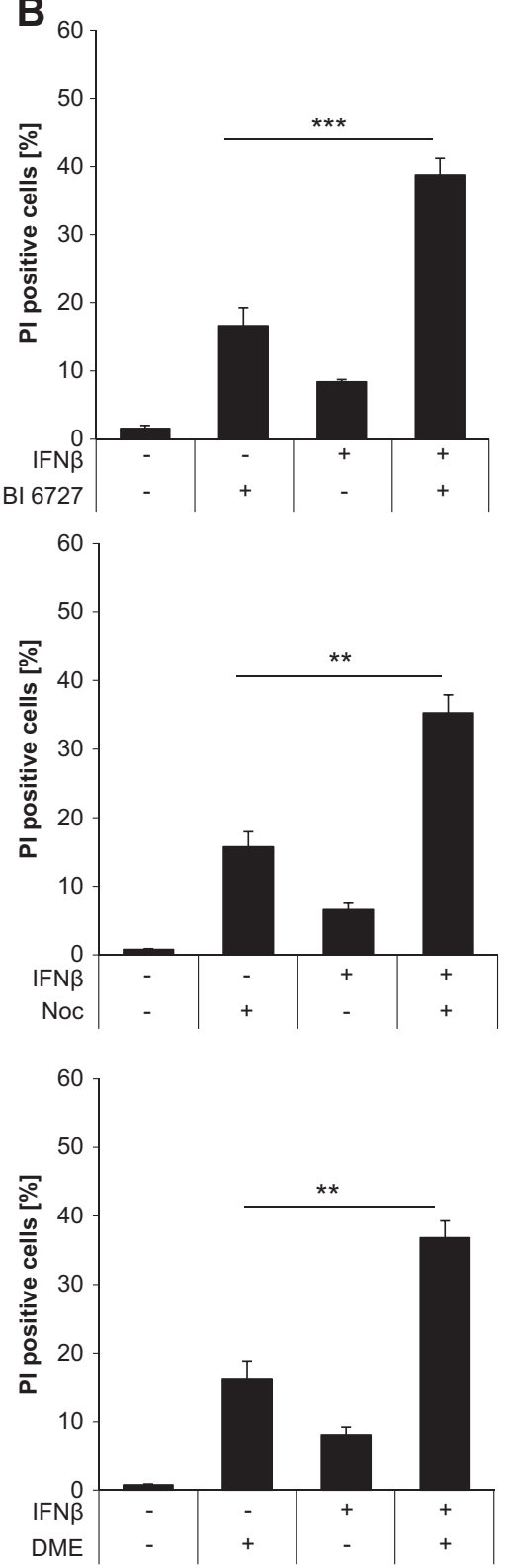

C
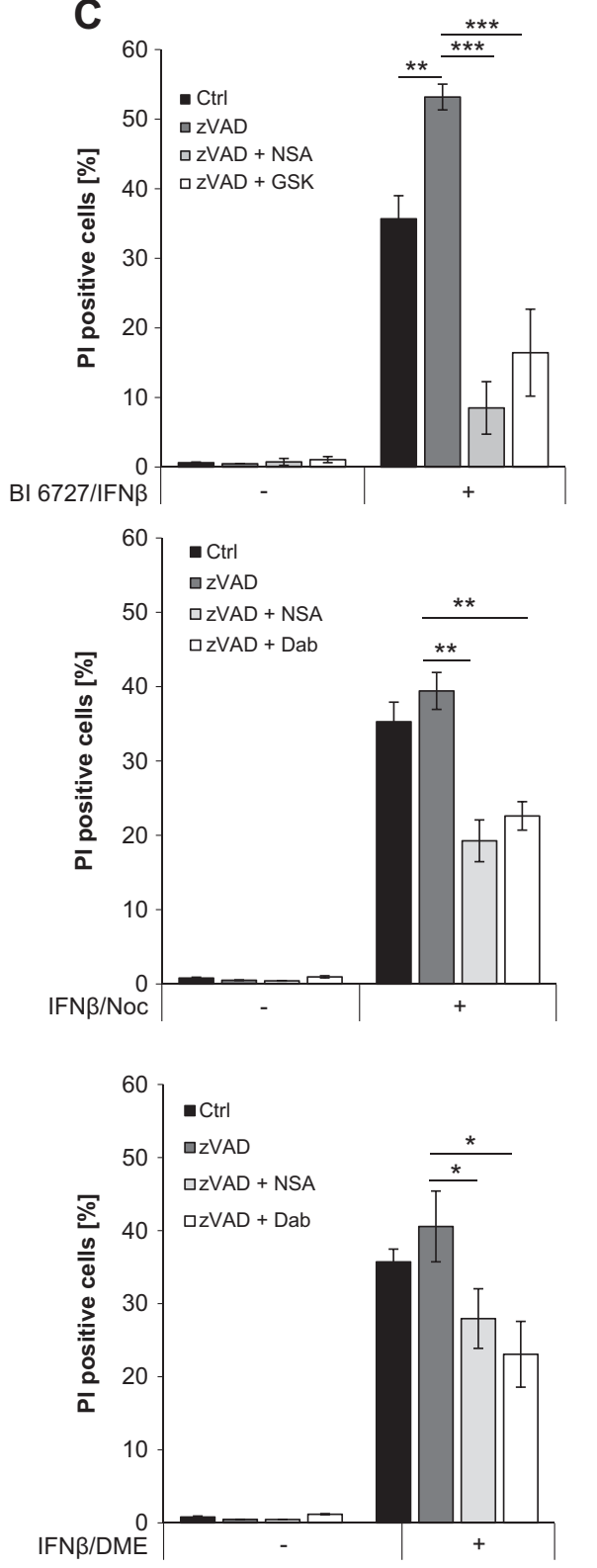

Fig. 5 Cell cycle arrest in mitosis induces RIP3 phosphorylation and enhances IFN $\beta$-induced necroptosis. a HT29 cells were treated with $10 \mathrm{ng} / \mathrm{ml} \mathrm{IFN} \beta, 10 \mathrm{nM}$ BI 6727, $1 \mu \mathrm{M}$ Noc or $2 \mu \mathrm{M}$ DME, and/or 20 $\mu \mathrm{M} z V A D$.fmk for $24 \mathrm{~h}$. Protein expression of RIP3, pMLKL, MLKL, and GAPDH was analyzed by Western blotting. GAPDH served as loading control. b HT2 9 cells were treated with $10 \mathrm{ng} / \mathrm{ml}$ IFN $\beta, 10 \mathrm{nM}$ BI 6727, $1 \mu \mathrm{M}$ Noc, and/or $2 \mu \mathrm{M}$ DME for $72 \mathrm{~h}$. Cell death was determined by analysis of PI-stained nuclei. Mean and SD of three

MLKL is only partial compared to prototypic necroptotic stimuli, indicating that additional forms of cell death besides necroptosis may contribute to the VNR/IFN $\beta / z V A D$.fmktriggered demise as well.

Notably, it has been described that RIP3-RIP3 interactions are sufficient to induce necroptosis, and RIP1-RIP3 interactions merely promote recruitment of more RIP3 to enhance autophosphorylation, MLKL recruitment, and independent experiments performed in triplicate are shown; $* P<0.05$, $* * P<0.01, * * * P<0.001$. c HT29 cells were treated with $10 \mathrm{ng} / \mathrm{ml}$ IFN $\beta, 10 \mathrm{nM}$ BI $6727,1 \mu \mathrm{M}$ Noc, and/or $2 \mu \mathrm{M}$ DME in the presence or absence of $10 \mu \mathrm{M}$ NSA, $20 \mu \mathrm{M}$ GSK' 872 , or $20 \mu \mathrm{M}$ Dab for $72 \mathrm{~h}$. Cell death was determined by analysis of PI-stained nuclei. Mean and SD of three independent experiments performed in triplicate are shown; $* P<0.05, * * P<0.01, * * * P<0.001$

subsequent necroptosis induction [35]. The switch from apoptosis to necroptosis of IFN $\beta$ and VNR co-treated cells upon caspase inhibition was also evident by increased phosphorylation of MLKL and inhibition of PARP cleavage after addition of zVAD.fmk. Additionally, we showed formation of multiprotein complexes of RIP1, RIP3, and MLKL upon TBZ treatment and, to a similar extent, upon VNR/IFN $\beta / z V A D$.fmk treatment. These multiprotein 
A

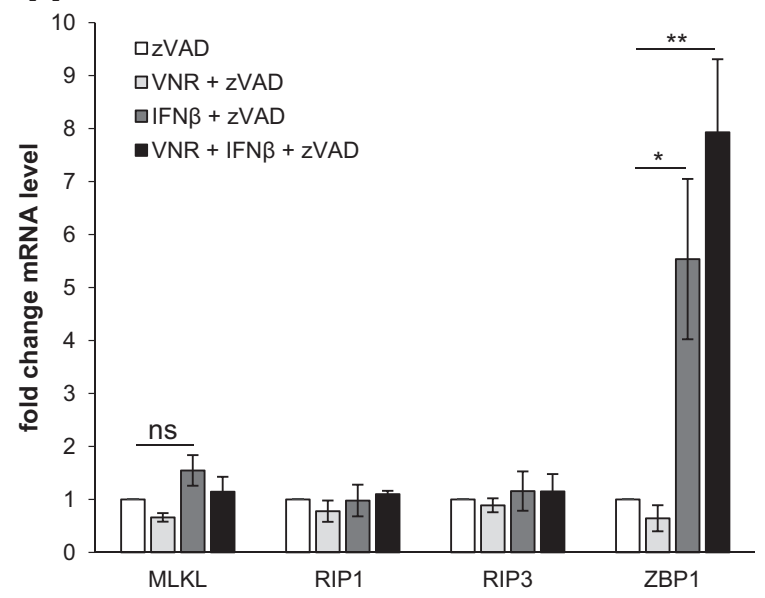

B
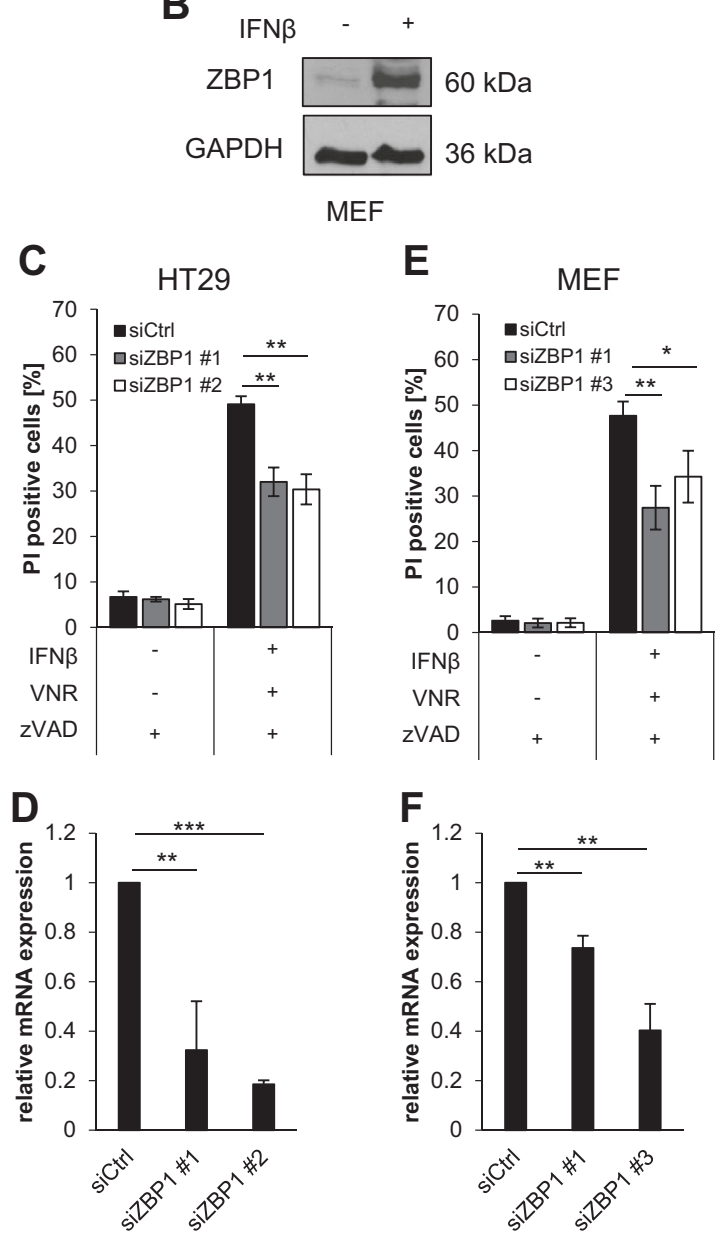

F
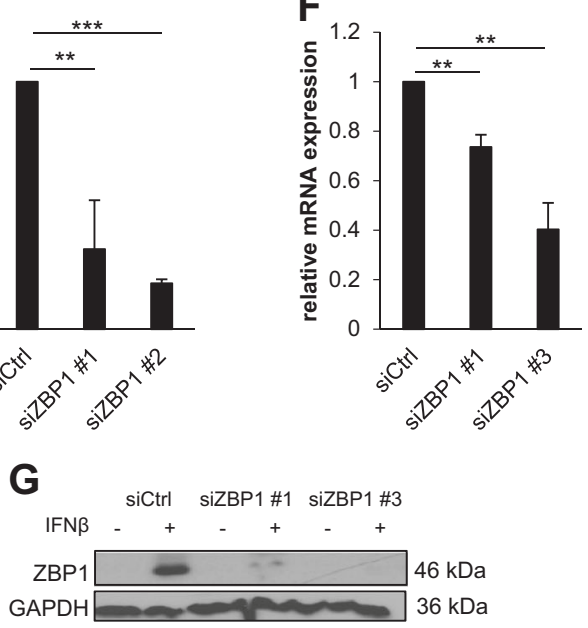

complexes correspond to the approximate size of the necrosome [36], which is needed to induce necroptosis, thereby supporting our findings that, upon caspase
Fig. 6 ZBP1 upregulation after IFN $\beta$ treatment is involved in cell death induction after VNR/IFN $\beta / z V A D$.fmk treatment. a HT29 cells were treated with $10 \mathrm{ng} / \mathrm{ml} \mathrm{IFN} \beta, 100 \mathrm{nM}$ VNR, and/or $20 \mu \mathrm{M}$ zVAD. fmk for $6 \mathrm{~h}$. mRNA expression of MLKL, RIP1, RIP3, and ZBP1 was determined by qRT-PCR, normalized to $28 \mathrm{~S}$ expression and is shown as $\mathrm{x}$-fold mRNA expression compared with the control. Mean and SD of three independent experiments performed in triplicate are shown; $* P<0.05, * * P<0.01$. b MEFs were treated with $4.5 \mathrm{ng} / \mathrm{ml}$ murine IFN $\beta$ for $24 \mathrm{~h}$. Protein expression of ZBP1 was assessed by Western blotting, GAPDH served as loading control. c-g HT29 cells (c, d) or MEFs (e-g) were transiently transfected with siRNA against ZBP1 or non-targeting control siRNA (siCtrl). Transfected cells were treated with $10 \mathrm{ng} / \mathrm{ml}$ IFN $\beta$ (HT29), $4.5 \mathrm{ng} / \mathrm{ml}$ murine IFN $\beta$ (MEFs), $100 \mathrm{nM}$ VNR, and/or $20 \mu \mathrm{M} z$ zVAD.fmk for $72 \mathrm{~h}$ (HT29) or $48 \mathrm{~h}$ (MEFs) and cell death was determined by analysis of PI-positive nuclei. Mean and SD of three independent experiments performed in triplicate are shown; $* P<0.05$, $* * P<0.01$. (c, e). Expression of ZBP1 was assessed by qRT-PCR, normalized to 28S (d; HT29) or murine GAPDH (f; MEFs) expression and is shown as $\mathrm{x}$-fold mRNA expression compared with the control. Mean and SD of three independent experiments performed in triplicate are shown; $* * P<0.01, * * * P<0.001$. Protein expression of ZBP1 in MEFs was additionally shown by Western blotting, with GAPDH serving as loading control (g)

inactivation, treatment with VNR and IFN $\beta$ induces necroptotic cell death.

Importantly, we discover that mitotic arrest causes phosphorylation of RIP3. This conclusion is supported by our findings showing that (i) vinca alkaloids or Noc, as well as Plk-1 inhibition or Eg5 inhibition stimulate RIP3 phosphorylation in parallel with cell cycle arrest in mitosis, (ii) phosphatase treatment impedes phosphorylation of RIP3 as well as phosphorylation of the mitotic protein BubR1, and (iii) RIP3 phosphorylation correlates with cell cycle arrest in $\mathrm{M}$ phase. Of note, our findings indicate that RIP3 is phosphorylated during mitosis independently of RIP1 or its own kinase activity. Previous studies have shown that RIP3 is phosphorylated at two different residues that are involved in necroptosis signaling. Phosphorylation of RIP3 at S199 (murine S204) was described to depend on its own kinase activity and to be required for the RIP1-RIP3 interaction [27, 37], whereas phosphorylation of RIP3 at S227 (murine S232) was reported to be RIP1-dependent and needed for interaction of RIP3 with MLKL [28, 38]. However, our findings show that the addition of RIP1 or RIP3 inhibitors did not further prevent M-phase-dependent phosphorylation of RIP3, suggesting that RIP3 might be phosphorylated by another, yet undefined kinase, which might be involved in cell cycle regulation.

Interestingly, we find that IFN $\beta$ treatment leads to a significant upregulation of ZBP1 mRNA levels, as well as protein expression and that knockdown of ZBP1 significantly reduces necroptosis after VNR/IFN $\beta$ / zVAD.fmk treatment, underscoring a pivotal role for ZBP1 in this system. ZBP1 expression has been described to be regulated by type I IFN signaling [39]. Recently, independent studies have shown that, depending on the signaling 
cascade, other RHIM domain-containing proteins, such as ZBP1 upon viral infection are able to bind RIP3 through their RHIM domains promoting necroptosis induction $[8$, 15]. In addition, ZBP1 has been reported to induce RIP3dependent necroptosis when RIP1 is absent or the RHIM domain of RIP1 is mutated [16, 17].

Our study provides a rationale for future (pre)clinical evaluation of IFN $\beta$ together with cell cycle regulators and especially microtubule-destabilizing drugs, such as vinca alkaloids. Currently, IFN $\beta$ is mainly used to treat multiple sclerosis [30]. However, recent findings also emphasize that IFNs can be used for cancer treatment as well. For example, IFN $\alpha$ synergizes with the Smac mimetic BV6 to induce apoptosis in myeloid leukemia cells and renal cell carcinoma [40, 41]. Similarly, IFN $\gamma$ and BV6 cooperate to induce necroptosis in several cancer entities [42] and IFN $\beta$ promotes temozolomide (TMZ)-induced cell death in glioblastoma cells [43]. Vinca alkaloids, as well as other microtubule-interfering drugs, are used in the clinic to treat a number of cancers including breast, ovarian, and lung cancer [44]. Additionally, a previous study showed that VNR synergizes with IFN $\alpha$ to improve the response rate of patients with metastatic renal cell carcinoma [45]. Our results indicating that VNR cooperates with IFN $\beta$ to induce cell death underscore these findings and point to improved anti-tumor responses of IFNs in combination with microtubule-destabilizing agents in clinical settings. The question as to whether or not the addition of IFNs to microtubule-destabilizing agents may also increase the toxicity of these agents to non-malignant normal cells will have to be taken into consideration in future studies.

In conclusion, our study provides novel insights into alternative mechanisms to induce necroptosis, thereby circumventing apoptosis resistance, which provides important implications for the development of future therapeutic regimens.

Acknowledgements We thank D. Bruecher for expert technical assistance and C. Hugenberg for excellent secretarial assistance.

Funding This work has been partially supported by grants from the BMBF (to S.F.).

\section{Compliance with ethical standards}

Conflict of interest The authors declare that they have no conflict of interest.

Publisher's note: Springer Nature remains neutral with regard to jurisdictional claims in published maps and institutional affiliations.

\section{References}

1. Hanahan D, Weinberg RA. Hallmarks of cancer: the next generation. Cell . 2011;144:646-74.
2. Fulda S. Tumor resistance to apoptosis. Int $\mathrm{J}$ Cancer. 2009;124:511-5.

3. Vanden Berghe T, Linkermann A, Jouan-Lanhouet S, Walczak H, Vandenabeele P. Regulated necrosis: the expanding network of non-apoptotic cell death pathways. Nat Rev Mol Cell Biol. 2014;15:135-47.

4. Pasparakis M, Vandenabeele P. Necroptosis and its role in inflammation. Nature. 2015;517:311-20.

5. Vanden Berghe T, Hassannia B, Vandenabeele P. An outline of necrosome triggers. Cell Mol Life Sci. 2016;73:2137-52.

6. Dondelinger Y, Declercq W, Montessuit S, Roelandt R, Goncalves A, Bruggeman I, et al. MLKL compromises plasma membrane integrity by binding to phosphatidylinositol phosphates. Cell Rep. 2014;7:971-81.

7. de Almagro MC, Vucic D. Necroptosis: pathway diversity and characteristics. Semin Cell Dev Biol. 2015;39:56-62.

8. Kaiser WJ, Sridharan H, Huang C, Mandal P, Upton JW, Gough PJ, et al. Toll-like receptor 3-mediated necrosis via TRIF, RIP3, and MLKL. J Biol Chem. 2013;288:31268-79.

9. Schneider WM, Chevillotte MD, Rice CM. Interferon-stimulated genes: a complex web of host defenses. Annu Rev Immunol. 2014;32:513-45.

10. McComb S, Cessford E, Alturki NA, Joseph J, Shutinoski B, Startek JB, et al. Type-I interferon signaling through ISGF3 complex is required for sustained Rip3 activation and necroptosis in macrophages. Proc Natl Acad Sci USA. 2014; 111:E3206-3213.

11. Legarda D, Justus SJ, Ang RL, Rikhi N, Li W, Moran TM, et al. CYLD proteolysis protects macrophages from TNF-mediated auto-necroptosis induced by LPS and licensed by Type I IFN. Cell Rep. 2016;15:2449-61.

12. Thapa RJ, Nogusa S, Chen P, Maki JL, Lerro A, Andrake M, et al. Interferon-induced RIP1/RIP3-mediated necrosis requires PKR and is licensed by FADD and caspases. Proc Natl Acad Sci USA. 2013;110:E3109-3118.

13. Robinson N, McComb S, Mulligan R, Dudani R, Krishnan L, Sad $\mathrm{S}$. Type I interferon induces necroptosis in macrophages during infection with Salmonella enterica serovar Typhimurium. Nat Immunol. 2012;13:954-62.

14. Kuriakose T, Kanneganti TD. ZBP1: innate sensor regulating cell death and inflammation. Trends Immunol. 2018;39:123-34.

15. Kuriakose T, Man SM, Subbarao Malireddi RK, Karki R, Kesavardhana $\mathrm{S}$, Place DE, et al. ZBP1/DAI is an innate sensor of influenza virus triggering the NLRP3 inflammasome and programmed cell death pathways. Sci Immunol. 2016; 1:aag2045.

16. Lin J, Kumari S, Kim C, Van TM, Wachsmuth L, Polykratis A, et al. RIPK1 counteracts ZBP1-mediated necroptosis to inhibit inflammation. Nature. 2016;540:124-8.

17. Newton K, Wickliffe KE, Maltzman A, Dugger DL, Strasser A, Pham VC, et al. RIPK1 inhibits ZBP1-driven necroptosis during development. Nature. 2016;540:129-33.

18. Kaiser WJ, Upton JW, Mocarski ES. Receptor-interacting protein homotypic interaction motif-dependent control of NF-kappa B activation via the DNA-dependent activator of IFN regulatory factors. J Immunol. 2008;181:6427-34.

19. Wood KW, Cornwell WD, Jackson JR. Past and future of the mitotic spindle as an oncology target. Curr Opin Pharmacol. 2001;1:370-7.

20. Matson DR, Stukenberg PT. Spindle poisons and cell fate: a tale of two pathways. Mol Interv. 2011;11:141-50.

21. Mollinedo F, Gajate C. Microtubules, microtubule-interfering agents and apoptosis. Apoptosis. 2003;8:413-50.

22. Perez EA. Microtubule inhibitors: differentiating tubulininhibiting agents based on mechanisms of action, clinical activity, and resistance. Mol Cancer Ther. 2009;8:2086-95. 
23. Hugle M, Belz K, Fulda S. Identification of synthetic lethality of PLK1 inhibition and microtubule-destabilizing drugs. Cell Death Differ. 2015;22:1946-56.

24. Heinicke U, Haydn T, Kehr S, Vogler M, Fulda S. BCL-2 selective inhibitor ABT-199 primes rhabdomyosarcoma cells to histone deacetylase inhibitor-induced apoptosis. Oncogene. 2018;37:5325-39.

25. Kotredes KP, Gamero AM. Interferons as inducers of apoptosis in malignant cells. J Interferon Cytokine Res. 2013;33:162-70.

26. Jackson JR, Patrick DR, Dar MM, Huang PS. Targeted antimitotic therapies: can we improve on tubulin agents? Nat Rev Cancer. 2007;7:107-17.

27. He S, Wang L, Miao L, Wang T, Du F, Zhao L, et al. Receptor interacting protein kinase-3 determines cellular necrotic response to TNF-alpha. Cell. 2009;137:1100-11.

28. Cho Y, Challa S, Moquin D, Genga R, Ray TD, Guildford M, et al. Phosphorylation-driven assembly of RIP1-RIP3 complex regulates programmed necrosis and virus-induced inflammation. Cell. 2009;137:1112-23.

29. Biziota E, Briasoulis E, Mavroeidis L, Marselos M, Harris AL, Pappas P. Cellular and molecular effects of metronomic vinorelbine and 4-O-deacetylvinorelbine on human umbilical vein endothelial cells. Anticancer Drugs. 2016;27:216-24.

30. Haji Abdolvahab M, Mofrad MR, Schellekens H. Interferon beta: from molecular level to therapeutic effects. Int Rev Cell Mol Biol. 2016;326:343-72.

31. Chen D, Tong J, Yang L, Wei L, Stolz DB, Yu J, et al. PUMA amplifies necroptosis signaling by activating cytosolic DNA sensors. Proc Natl Acad Sci USA. 2018;115:3930-5.

32. McArthur K, Whitehead LW, Heddleston JM, Li L, Padman BS, Oorschot V, et al. BAK/BAX macropores facilitate mitochondrial herniation and mtDNA efflux during apoptosis. Science. 2018;359. pii: eaao6047.

33. Riley JS, Quarato G, Cloix C, Lopez J, O'Prey J, Pearson M, et al. Mitochondrial inner membrane permeabilisation enables mtDNA release during apoptosis. EMBO J 2018;37. pii: e99238.

34. Czabotar PE, Lessene G, Strasser A, Adams JM. Control of apoptosis by the BCL-2 protein family: implications for physiology and therapy. Nat Rev Mol Cell Biol. 2014;15:49-63.
35. Wu XN, Yang ZH, Wang XK, Zhang Y, Wan H, Song Y, et al. Distinct roles of RIP1-RIP3 hetero- and RIP3-RIP3 homo-interaction in mediating necroptosis. Cell Death Differ. 2014;21: 1709-20.

36. de Almagro MC, Goncharov T, Izrael-Tomasevic A, Duttler S, Kist M, Varfolomeev E, et al. Coordinated ubiquitination and phosphorylation of RIP1 regulates necroptotic cell death. Cell Death Differ. 2017;24:26-37.

37. Sun X, Yin J, Starovasnik MA, Fairbrother WJ, Dixit VM. Identification of a novel homotypic interaction motif required for the phosphorylation of receptor-interacting protein (RIP) by RIP3. J Biol Chem. 2002;277:9505-11.

38. Sun L, Wang H, Wang Z, He S, Chen S, Liao D, et al. Mixed lineage kinase domain-like protein mediates necrosis signaling downstream of RIP3 kinase. Cell. 2012;148:213-27.

39. Takaoka A, Wang Z, Choi MK, Yanai H, Negishi H, Ban T, et al. DAI (DLM-1/ZBP1) is a cytosolic DNA sensor and an activator of innate immune response. Nature. 2007;448:501-5.

40. Bake V, Roesler S, Eckhardt I, Belz K, Fulda S. Synergistic interaction of Smac mimetic and IFNalpha to trigger apoptosis in acute myeloid leukemia cells. Cancer Lett. 2014;355: 224-31.

41. Reiter M, Eckhardt I, Haferkamp A, Fulda S. Smac mimetic sensitizes renal cell carcinoma cells to interferon-alpha-induced apoptosis. Cancer Lett. 2016;375:1-8.

42. Cekay MJ, Roesler S, Frank T, Knuth AK, Eckhardt I, Fulda S. Smac mimetics and type II interferon synergistically induce necroptosis in various cancer cell lines. Cancer Lett. 2017;410:228-37.

43. Marschall V, Fulda S. Smac mimetic-induced upregulation of interferon-beta sensitizes glioblastoma to temozolomide-induced cell death. Cell Death Dis. 2015;6:e1888.

44. Pellegrini F, Budman DR. Review: tubulin function, action of antitubulin drugs, and new drug development. Cancer Invest. 2005;23:264-73.

45. Schmidinger M, Steger GG, Budinsky AC, Wenzel C, Brodowicz $\mathrm{T}$, Locker GJ, et al. Vinorelbine and interferon-alpha2c as secondline therapy in metastatic renal cell carcinoma. Anticancer Drugs. 2000;11:175-9. 